\title{
ACTIVITIES OF THE STUDENT FORUM OF THE GEOINFORMATION FORUM JAPAN
}

\author{
A. Oba ${ }^{\text {a }}$, H. Miyazaki ${ }^{\text {b }}$ \\ ${ }^{a}$ Graduate School of Media and Governance, Keio University, Endo 5322 Fujisawa Kanagawa, 252-0816, Japan - \\ perry@sfc.keio.ac.jp \\ ${ }^{\mathrm{b}}$ Center for Spatial Information Science, The University of Tokyo, 5-1-5 Kashiwanoha Kashiwa-shi Chiba, 277-8568, \\ Japan - heromiya@csis.u-tokyo.ac.jp
}

Youth Forum

KEY WORDS: Student Forum, Geoinformation Forum, Academic Activities, Youth Network, Japan

\begin{abstract}
:
This reports a history and future prospects of the activities by the Student Forum of the Geoinformation Forum Japan. For growths of academic fields, active communications among students and young scientists are indispensable. Several academic communities in geoinformation fields are established by youths and play important roles of building networks over schools and institutes. The networks are expected to be innovative cooperation after the youths achieve their professions. Although academic communities are getting fixed growth particularly in Japan, youths had gotten little opportunities to make contacts with youths themselves. To promote gotten youth activities among geoinformation fields, in 1998, we started a series of programs that named the Student Forum of the Geoinformation Forum Japan involving students and young scientists within the annual conferences, Geoinformation Forum Japan. The programs have provided opportunities to do presentation their studies by posters, some events, and motivations to create networks among students and young scientists. From 2009, some members of our activities set additional conference in west area of Japan. Thus our activities are spread within Japan. As a result of these achievements, the number of youth dedicating to the programs keeps growing. From 2009, it's getting international gradually, however, almost all the participants are still Japanese. To keep and expand the network, we are planning to make some nodes with some Asian youth organizations in the field of geoinformation. This paper is concluded with proposals and future prospects on the Student Forum of the Geoinformation Forum Japan.
\end{abstract}

\section{INTRODUCTION}

Generally, active communications among students and young scientists are indispensable for developing of academic fields. Therefore, academic communities in some acadmic fields were established by each academic conference. These communities play important roles of building networks over schools and institutes. This network is expected to be innovative cooperation after the youths achieve their professions. Although academic communities are getting fixed growth particularly in Japan, youths had gotten little opportunities to make contacts with youths themselves. To promote gotten youth activities among geoinformation fields, Student Forum was organized for interdisciplinary communication among students of geoinformation technique, science and application in 1998 by courtesy of Japan Association of Surveyors (JAS).

In recent years, the academic activities of students often can be seen in other academic fields. On the other hand, sustainable activities become one of subjects for the future of geoinformation developement in Japan. Youth interests to this field are very important. Therefore, Student Forum of Geoinformation Forum also plays very imporatant role for sustainable developments in geoinformation field in Japan. This reports a history and future prospects of the activities by the Student Forum of the Geoinformation Forum Japan through the number of participants, contents and spreading activities in Japan.

\section{METHOD}

\subsection{Committee}

Operation is performed by volunteer activities. Members are consisted of chair student, student members, academic adviser and education director. Basically, student members manage committee by themself. Committee members are recruited by public offering. Members are applied from a variety of fields and universities based on geoinformation society by public offering. This PR message is sent to a mailing list of interested parties of this forum or put on website (Student Forum at Gspatial EXPO, 2012). In addition, committee members are in universities across Japan, meeting is conducted by teleconference on the Internet.

\subsection{Contents of Student Forum}

Student Forum of Geoinforimation Forum basically consists of 4 parts.

2.2.1 Lab Introduction: Participants explained about their laboratory by the slide show. To encourage their understanding between participants is indispensable for academic communication. This forum conducts a short presentation of the flash and talk about one minute, thus participants can be interested in activities of other laboratories. 
2.2.2 Poster Session: Poster session is a main event of Student Forum. Participants explain and discuss about their academic themes and topics by following their submitted paper to forum.

2.2.3 Exchange Event: Exchange event with participants has been started since 2008. One of committee members plans and makes some quizzes. Participants make groups, and each group has one answer in each quiz question. Through this event, participants can communicate with students who study or research other field. After finished student forum, committee has a reception for participants. Also, participants can talk and

2.2.4 Guest Lecture: Committee invite a guest speaker who works in geoinformation field. Through this lecture, participants have interests in their future as a job in geoinformation field.

\subsection{Public Relations}

Committee members make a original list for public relations. They make lists of professors and some mailing lists of laboratories and academic conferences that relate with geoinformation field thorough accessing their Web sites. Basically, public relations of Student Forum are sending messages to these professors and mailing lists.

\subsection{Devisal for Participant Benefits}

Student Forum has 2 types of devisal as participant benefits. At first, poster session awards are praised from the chair of Japan Association of Surveyors (JAS) in public. 3 participants or teams can get these awards.

Secondly, participants get chances to make a relationship with business partners. This forum is held in Geoinformation Forum. Many technical experts come to Geoinformation Forum due to their exhibition, therefore they also come to Student Forum. If participants make good presentations, some can get chances to go to related companies.

\section{RESULT}

\subsection{Number of Participants and Changes}

As a result of activities in the committee of Student Forum, we have a result in the number of participants in Figure 1. From 1999 to 2004, the number of participants increased, and after 2005, it repeatedly increased and decreased between approximately 45 to 55 participants.

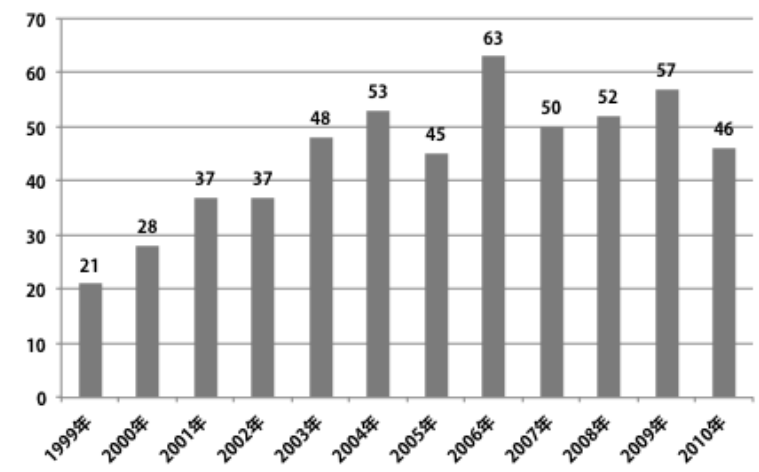

Figure 1. Number of Participants from 1999 to 2010

\subsection{Spreading Communities}

From 2009, some members of Student From Committee set

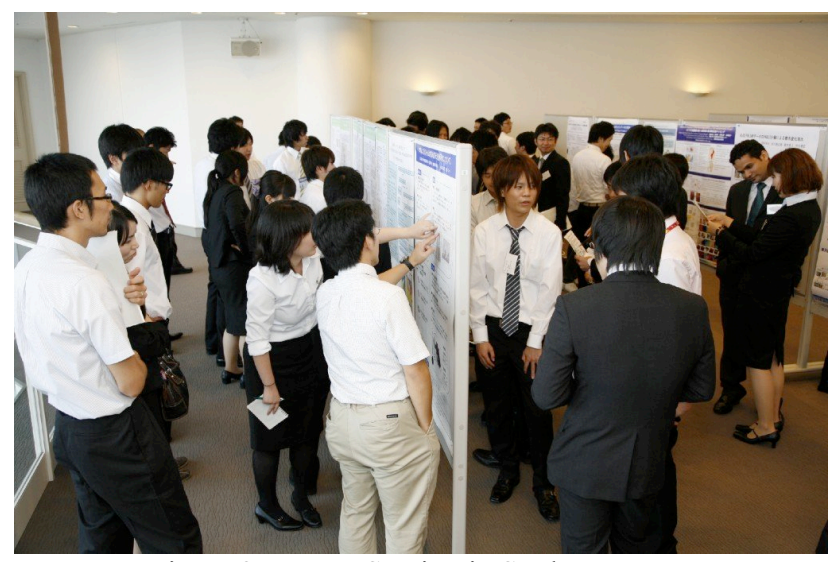

Figure 2. Poster Session in Student Forum

additional conference in west area of Japan. As early as next year 2010, their forum is developed, other geoinformation conference in Japan started support their activities.( that names Geospatial Information Forum for Students and Young Engineers in Kansai, 2011). As a result of these achievements, the number of youth dedicating to the programs keeps growing. And also from 2009, it's getting international gradually. English contents and information is started in web site and conference. Numbers of foreign participants are 3 in 2009 and 1 in 2010.

\section{DISCUSSION}

The cause of participants increase from 1999 to 2004 can be thought that it was effect of spread public relations. After 2005, Increased and decreased was repeatedly occurred, but also it seems stable. The background to this point may be mentioned by e-mail publicity was effective and reported by participants and committee members that there was a cooperation of famous professors in west universities. And also there was some merit for participants to make a relationship with business partners in related companies, and get awards, such as all students belong. In addition, students could show their presentation by not only posters but also architectural and landscape models. This architecture presentation is exhibited in a group model, and a number of students discussed around the model. It has shown new possibilities in the way of poster session in Student Forum.

\section{CONCLUSION}

This reports a history and future prospects of the activities by the Student Forum of the Geoinformation Forum Japan. Committee system and contents of this forum can make benefits for participants and interests to geoformation fields. To keep and expand the network, we are planning to make some nodes with some Asian youth organizations in the field of geoinformation.

\section{References from websites:}

Geospatial Information Forum for Students and Young Engineers in Kansai, 2011. What is Geospatial Information Forum for Students and Young Engineers in Kansai? Japan. https://sites.google.com/site/kansaiwakategis/home (22 Nov. 2011).

Student Forum at G-spatial EXPO, 2012. Report on the Joint ISPRS Commission III/IV Workshop "3D Reconstruction and Modeling of Topographic Objects”, Stuttgart, Germany. http://gi-studentjp.co.cc/s_forum/ (10 Apr. 2012). 